\title{
Publisher's Note: Phase-field study of ripening and rearrangement of precipitates under chemomechanical coupling [Phys. Rev. B 95, 174101 (2017)]
}

\author{
C. Schwarze, A. Gupta, T. Hickel, and R. Darvishi Kamachali
}

(Received 1 June 2017; published 7 June 2017)

DOI: 10.1103/PhysRevB.95.219904

This paper was published online on 9 May 2017 with an error in the text on page 5. On page 5, the sixth line in the right-hand column should read as " $2 \times 2 \times 2-14 \times 14 \times 14 k$ points, respectively, for $\mathrm{Al}_{107} \mathrm{Li}_{1}$ supercell." The paper has been corrected as of 30 May 2017. The text is correct in the printed version of the journal. 